\title{
A Novel Approach To Undergraduate Decision Sciences Curriculum
}

\author{
Carol Markowski, Old Dominion University, USA
}

\begin{abstract}
This paper describes an unusual approach to the incorporation of decision sciences in the core business curriculum as well as a novel undergraduate major in decision sciences.
\end{abstract}

Keywords: Curriculum, Decision Sciences, AACSB

\section{INTRODUCTION}

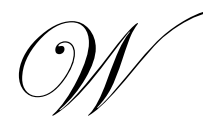

hen students say that they are taking a course in decision sciences or that they are decision sciences majors, the typical reaction is the question, "What is that?" If the student replies that it is a combination of probability, statistics, management science, and operations management, the reaction is usually a groan and comment about how they once had to take a course in statistics and how much they hated it. "There were so many formulas! Why would anyone want to major in anything like that?" Even most colleagues on business faculties cringe at the thought of the simplex method. This paper describes an uncommon approach to the incorporation of decision sciences in the core business curriculum as well as a novel undergraduate major in decision sciences. How other schools address each of these topics will also be presented.

\section{DECISION SCIENCE IN THE BUSINESS CORE}

AACSB has varied its approach to decision sciences education over the years. Early on, prior to 1991, coverage of statistics, management science and production were required (Grossman, 2003). Many schools offered a two semester sequence in probability and statistics, a course in management science and a course in production/operations management. Between 1991 and 2003, the organization dropped mention of management science. As a consequence, most schools dropped their management science course from the core or they combined some of the content with that of production in an operations management course. The approach presented in this paper differs from most. The 2003 standards no longer have a list of required topics, but they identify topics which would typically appear in a general management degree program. Statistical data analysis, management science, and production are all listed. It is up to the individual school to determine what is appropriate to support its mission and learning goals. Whatever choices are made should be both current and relevant to the needs of business and management positions (AACSB).

As AACSB has changed over the years, so have other things. One of the most striking has been the progress in hardware and software technology. Many of us learned statistics and linear programming without the aid of software. With numerous choices of student versions of software for each, this is no longer the case for most students. In essence, curriculum has changed. Faculty can cover more topics, stress different things, or do both. In that vein, the novel approach described below for the core curriculum at Old Dominion University evolved.

The first course, offered at the sophomore level, is called Probability, Decision Analysis, and Statistics for Business and Economics. It includes coverage of common topics such as descriptive statistics, the binomial and normal distributions, sampling distributions, confidence intervals and one sample hypothesis testing. What makes this course unusual is the increased emphasis on probability, particularly Bayes Rule, and coverage of decision analysis with and without probabilities. Typically, decision analysis is covered in a management science course, but this approach introduces it after instruction on Bayes Rule. This provides a high level application of the probability principles just covered, builds upon the concept of the expected value of a discrete distribution, and permits a 
smooth tie in with decision analysis with sample information. Incorporating decision analysis into the course requires a few weeks and is considered by most students to be the most difficult topic in the course. This necessitates decreased time on topics such as descriptive statistics. Rather than hand calculations of standard deviations, histograms, etc. software permits more important activities regarding how to use the statistics and what statistic is appropriate in various circumstances. The emphasis on analysis rather than computation throughout the course frees the time to incorporate decision analysis.

The second course in this sequence is offered at the junior level and is called Statistical Data Analysis and Management Science. Topics include two sample hypothesis testing, one way analysis of variance, analysis of frequency data, correlation analysis, simple and multiple regression, time series forecasting, linear programming formulation and managerial analysis, distribution models and PERT/CPM models. This course depends heavily on the use of software. Emphasis is on formulation and interpretation of business problems. An attempt is made to provide applications relevant to accounting, economics, finance, human resources, information systems, marketing, and production. In both courses, the student version of MINITAB is used for statistical analysis. The second course utilizes user friendly management science software provided with some management science textbooks.

A distinct course in operations management is also required. It examines strategic, tactical, and operational issues in the planning and control of manufacturing and service delivery systems. Although it is part of the business core, it also satisfies a technology general education requirement for the university. In order to achieve that end, inclusion of topics that are not necessarily found in the typical OM class were required. Examples include ethical issues, history of technology, and the economic and societal impact of technological advances. In addition to these topics, the course also includes such traditional topics as process design, capacity and materials planning, inventory management, scheduling, quality management, facility layout, and work measurement. Although some schools try to incorporate management science techniques, such as what is presented in the second course in the sequence, the proposed approach emphasizes conceptual knowledge of operations with simple algebraic tools as support. As many schools have a course that is somewhat similar to this, this paper will not further address the inclusion of operations in the core.

The proposed unusual sequence has its advantages and disadvantages. The main advantage of the program is the educational benefit. The courses cover probability and statistics as well as the most used management science topics in depth and they do so in an efficient manner. Although students find the courses difficult and fast paced, they learn how to read critically, analyze situations, and provide recommendations in a management context. They see the relevance to actual business situations as evidenced by students who are already in the workplace and constantly find uses for the subject and the software. Business executives have said that they value the ability to communicate and the ability to analyze situations much more than any specific knowledge obtained from a given class. One of the goals of this sequence is to achieve their desires. Given that the sequence is supposed to begin in the sophomore year, students have plenty of time to hone these abilities in future classes.

The major disadvantage is the problem of dealing with transfers. Because of the rarity of the program, students become upset when a previous course in statistics taken at another school is not considered equivalent to either of those in the sequence. In order to alleviate part of the problem, the local community college developed an equivalent course because the majority of their students transfer to Old Dominion University. If students have a two course sequence in probability and statistics and a course in management science, credit is given for the current sequence. Based upon research on a sample of schools, only a few schools have a required two course sequence incorporating probability, statistics, and management science, i.e. something similar to the proposed curriculum. In fact the majority of schools require only a single overview course in statistics which is sometimes offered within the business curriculum but more often is taught by faculty in a mathematics department. When students transfer with either one or two statistics courses, they must learn the material and pass a waiver exam on the management science portion of the first course in order to get transfer credit for the first course.

\section{UNDERGRADUATE DECISION SCIENCES MAJOR}

Very few schools offer an undergraduate major in Decision Sciences where the thrust of the program is management science rather than operations management or information systems. Recently supply chain 
management majors have been popping up. They have mostly replaced the former operations management major which many schools dropped in the 1990's. In fact the Decision Sciences major proposed here was a consequence of such action. Because of cost cutting, the state wanted to cut back on programs with few students. If fewer courses had to be taught, fewer faculty would be necessary and dollars would be saved. We proposed a somewhat interdisciplinary Decision Sciences major in order to maintain a business program with a quantitative thrust. We already had a minor which included the second course in the core sequence, the operations management course, both of which were described above, a course in advanced management science and one in simulation. The minor had a sufficient number of students to keep it safe from the cut. In order to develop the major, we added courses from information systems, primarily programming courses, and from other disciplines as what we refer to as a functional area. Originally, there were functional areas in accounting, economics, finance, human resources management, marketing and operations. Each functional area required an international course as well as two approved upper level courses. For example, a student could get a functional area in marketing by taking the multi national marketing class as well as a class in marketing of services and another class in marketing on the internet. The major has transformed over time by replacing required information systems courses with decision sciences electives, but the functional area concept still exists. In the 2008 catalog, we will offer functional areas in accounting, economics, finance, human resource management, information technology, international business, maritime and supply chain management, and marketing. Students choose two courses from the decision sciences electives: forecasting and quality management systems, supply chain management and logistics, and spreadsheet modeling. In addition, they choose one course from a list of quantitatively oriented classes such as marketing research, investments, or introduction to mathematical economics offered by the other disciplines. Three courses in the functional area complete the major requirements.

The concept of the major is that students may find jobs in their functional area, but they are better prepared than most to perform analysis. With so many students majoring in marketing or human resource management, the decision sciences major sets them apart. Very few schools have undergraduate majors in decision sciences. Most similar majors are found at the graduate level and most are found in math or engineering rather than in business. They tend to be very mathematically oriented. Our program is application oriented and does not require more than the basic level of applied calculus that all of our business majors are required to take. The only school sampled which employs anything like functional areas is MIT. In fact the undergraduate program in the Sloan business school is called management science. The five required core courses are very mathematically oriented. In addition they choose four courses from concentration areas in finance, information technology, marketing and operations research (mostly operations management). In other words, they replace the traditional business core with the management science courses. A few other schools have undergraduate majors in decision sciences within the undergrad business administration degree. These include California State University at Fullerton and University of North Texas. Others such as University of Miami describe their major as management science, but in fact they have a very strong bent toward information technology. Miami University of Ohio has a decision sciences major with a strong statistics orientation in addition to information systems, but only current students may choose the program. It appears as if another program will disappear in favor of a pure information systems approach. University of South Carolina's management science major is actually information systems or operations /supply chain management. (Note that the references contain the web sites for each of these program descriptions.) None of the above employs the functional area concept.

The advantage of this major with the functional area concept is that it provides the quantitatively oriented students an opportunity to showcase their skills within a traditional area of business and subsequently makes them very marketable. In addition, it does not require the school to invest significant resources in the additional major.

\section{CONCLUSION}

Most schools reacted to changes in AACSB standards by reducing probability and statistics coverage to a minimum and dropping management science from its core curriculum and dropping or never developing a decision science major from the business administration degree. The approach taken by Old Dominion University maintains significant coverage of quantitative methods in the core by combining probability, statistics, and management science topics in an atypical two course sequence and offers a decision science major with a minimal amount of resources by utilizing courses from other disciplines in a functional area concept. 


\section{REFERENCES}

1. AACSB International: http://www.aacsb.edu/resource centers/assessment/std-curriculum-contents.asp

2. California State University at Fullerton: http://business.fullerton.edu/undergraduate/mgmtsci.htm

3. Grossman, Thomas A. "Getting Down to Business", OR/MS Today, Vol. 30, \#4, August 2003.

4. Massachusetts Institute of Technology: http://mitsloan.mit.edu/undergrad/academics.php

5. Miami University of Ohio: www.fsb.muohio.edu/departments/dsc-mis/undergraduate/major-requirements

6. Old Dominion University Undergraduate Catalog, Volume LXV, 2008.

7. University of Miami: www6.miami.edu/umbulletin/und/bus/mansci.htm

8. University of North Texas: www.coba.unt.edu/itds/bba ds.php

9. University of South Carolina: www.mooreschool.sc.edu/moore/mgsc/

\section{NOTES}

